\title{
Flood Risk Management in Malaysia: The current hindrances for flood related agencies
}

\section{Nurul Ashikin Mabahwi ${ }^{1}$, Hitoshi Nakamura ${ }^{2}$, Yasmin Bhattacharya ${ }^{3}$}

\author{
${ }^{1}$ Graduate School of Engineering and Science \\ 2Department of Planning, Architecture and Environmental Systems \\ ${ }^{3}$ SIT Research Laboratories \\ Shibaura Institute of Technology, Japan \\ na18102@shibaura-it.ac.jp, nakamu-h@shibaura-it.ac.jp, yasmin@shibaura-it.ac.jp
}

\begin{abstract}
Flood risk management in Malaysia is a top-down government approach that requires shared responsibility in between government agencies. However, the issues and challenges faced by the relevant agencies is a neglected area of research. This paper aimed to identify the real issues and challenges of flood-related agencies in Malaysia. This paper used a qualitative approach to analyse the findings and found that limited authority, lack of enforcement power, lack of cooperation and collaborative risk-sharing, insufficient funding, lack of assets and manpower and communication issues are the issues faced by flood-related government agencies.
\end{abstract}

Keywords: flood-related agencies; flood risk management; flood law and policy; Malaysia

eISSN: 2398-4295 @ 2020. The Authors. Published for AMER ABRA cE-Bs by e-International Publishing House, Ltd., UK. This is an open access article under the CC BY-NC-ND license (http://creativecommons.org/licenses/by-nc-nd/4.0/). Peer-review under responsibility of AMER (Association of Malaysian Environment-Behaviour Researchers), ABRA (Association of Behavioural Researchers on Asians / Africans / Arabians) and cE-Bs (Centre for Environment-Behaviour Studies), Faculty of Architecture, Planning \& Surveying, Universiti Teknologi MARA, Malaysia.

DOI: https://doi.org/10.21834/ajbes.v5i19.190 


\subsection{Introduction}

Floods are a significant disaster affecting Malaysia annually. Geographically, Malaysia experiences seasonal monsoon winds that bring heavy monsoon rains to the North and East Coast of Malaysia. Other than that, rainfall intensity is very high all year round, and the urban areas are affected by flash flooding (Chan, 2012b). Specifically, two types of flooding usually occur in Malaysia, which is the monsoon flood and flash flood. Monsoon flood happens typically around May until August (Southwest Monsoon) and around November until February (Northeast Monsoon) (Austin \& Baharuddin, 2012; Tan et al., 2015; Yusoff et al., 2018). On the other hand, flash flood usually happens in a busy city. It is caused by the uncontrolled human activities such as infrastructure development near the river areas and uncontrolled littering causing clogged drains and waterways (Othman et al., 2014; Sipon et al., 2015; Yusoff et al., 2018).

To date, flood risk management (FRM) in Malaysia has been a top-down government responsibility, and the Malaysians are heavily reliant on a top-down government-controlled techno-centric approach to flood management (Chan, 2012a). Huntjens et al., 2010 stated that 'top-down approach' means centralization of authority, a role that can include encouraging participatory processes. That is why in Malaysia, flood risk management is not merely about flood risks, but also comprises of a specific government system that encapsulates management perspective that combines prevention, mitigation, preparedness and response.

In Malaysia, flood risk management is divided by the management of the Federal Government, State Government and District Government (CFE-DM, 2016; Chan, 1995, 2012; Chong and Kamarudin, 2017). In each of this division, flood risk management is thus subject to the different legal framework, rules, policies, the standard of procedure and work practice. However, primary coordination, disaster funding, order and responsibilities on crisis management have remained at the federal level. This makes Malaysia a valuable case study in investigating the issues and challenges faced by flood-related agencies.

From the outside, it might look like the FRM in Malaysia is a collaborative risk-sharing and risk management at all levels of government with all relevant stakeholders. However, this paper argues that there are many hidden challenges in flood-related government agencies, such as National Disaster Management Agency (NADMA), Local Authority, Land and District Office, PLAN Malaysia, Department of Irrigation and Drainage (DID), Malaysia Civil Defence Force (APM), Fire and Rescue and the Police Department, National Hydraulic Research Institute of Malaysia (NAHRIM).

Our study aimed to identify the real issues and challenges of flood agencies in Malaysia. Why is it crucial to identify the issues and challenges of these agencies? This is because the analysis of the flood-related agencies itself will make a crucial contribution to assessing and strengthening the agencies capacities needed for better and comprehensive flood risk management. The weaknesses or strengths of related agencies will either threaten or favour the whole flood risk management process. 


\subsection{Literature Review}

Implementing FRM requires effective collaboration, clear communications, and well-defined roles, responsibilities, and authorities at all levels of government, the private sectors, non-governmental organizations, and the public (Traver, 2014). The importance of collaboration in flood risk management has been mentioned as a key point of professionalism in FRM activities since there appears to be limitation in a single authority (Raungratanaamporn et al., 2014). The FRM in Malaysia is a top-down government approach and a shared responsibility in between federal, state and district.

In Malaysia, management of flood risks is regulated by Directive No. 20 under the auspices of the NADMA. Directive No. 20 is an executive order by the Prime Minister Office consists of disaster management mechanisms for before disaster, during the disaster and after the disaster. Every government agency involved with disaster must act according to what is written in the executive order (in this case flood is categorized as 'disaster' in Directive No. 20). Under Directive No. 20 , there are five stages in the disaster management cycle, consisting prevention, mitigation, preparedness, response and recovery.

As stated in Directive No. 20, flood risk management requires coordination, corporation and commitment between flood-related agencies. However, a study by (Beamon, 2004) has revealed that the coordination of supply between agencies involved in disaster relief is challenging. Meanwhile, Shahid, Xinhai et al., 2014 claims that inter-agency coordination challenges during disasters are a well-known area, but a neglected area of research. In 2011, Salmon et al. stated that the challenges of disaster agencies are due to unpredictable outcomes, massive causalities, shortages of resources, lingering side effects, disruption of public service, collapsed infrastructures, enormous time pressures, high stakes, highly interdependent tasks and communication breakdowns. These conditions are further aggravated by personal or organizational conflicts in authorities, interest or motives.

Furthermore, disaster management agencies in Sri Lanka faced the issues of the inadequate legal framework, limited authority, outdated ordinances to support disaster risk reduction, lack of adequate tools, techniques and guidelines, human resource constraints, funding constraints and weaknesses in the internal and external systems (Chamindi et al., 2016).

For Malaysia, a study by Chong and Kamarudin (2017), identified three main challenges faced by disaster agencies in Malaysia. The challenges are unproportioned disaster management planning between top-down and bottom-up approaches, lack of coordination in the entire disaster management cycle and a greater focus on the disaster emergency response stage, and insufficient planning for a long-term recovery (post-disaster) process that results in lack of community and stakeholder resilience towards disasters.

\subsection{Methodology}

This study used primary and secondary data to identify issues and challenges of flood-related agencies in Malaysia. By employing a qualitative approach, the primary data was collected through face-to-face interview in January 2020 to 27 government officials of flood-related government agencies in Malaysia. Agencies involved in this interview were DID (federal, state 
and district level), Local Authorities, NADMA, Police Department, District Councils, Malaysia Civil Defence Force, Land and District Offices, Fire and Rescue Department, PLANMalaysia, NAHRIM and Stormwater Management and Road Tunnel (SMART). Secondary data were gathered through a systematic literature review on government reports, research papers, journals and books.

Data gathered were analysed using a qualitative thematic analysis. It is a method for determining, analysis and reporting themes within the text and useful for theorising across many cases and finding common patterns across the research participants (Fereday \& Muir-Cochrane, 2006; Riessman, 2005; Mohamed and Ragab, 2016). This technique permits the researcher to combine meanings behind respondents' statement within their particular context (Joffe and Yardley, 2004; Mohamed and Ragab, 2016). For this study, data collected during the interviews were analysed, classified, and appropriately coded to determine the relevant themes for further discussion. The themes identified were authority, collaborative, cooperation, manpower, logistics, funding and communication.

\subsection{Results}

There are various issues and challenges faced by flood-related government agencies in Malaysia.

Table 1 summarises the issues and challenges:

Table 1: Summary of the issues and challenges

\begin{tabular}{cll}
\hline Sub-topic & \multicolumn{1}{c}{ Issues and challenges } & \multicolumn{1}{c}{ Agencies } \\
\hline 4.1 & $\begin{array}{l}\text { Limited authorities and lack of enforcement } \\
\text { power }\end{array}$ & DID, NADMA \\
4.2 & $\begin{array}{l}\text { Collaborative risk sharing and risk management } \\
\text { at all levels of government }\end{array}$ & All agencies \\
4.3 & Lack of cooperation among agencies & Civil Defence, Fire \\
& & and Rescue, DID, \\
& & Local Authority, \\
& & PLANMalaysia, \\
& & Land and District \\
4.4 & No no establishment of long term, reliable & Office \\
& funding mechanisms for flood risk reduction & Defence, Fire and \\
& measures at the federal, state, and local levels & Rescue, Police \\
& & Department \\
4.5 & Lack of manpower and assets for logistics & Civil Defence, Fire \\
& & and Rescue, Police \\
& & Department, DID, \\
& & NADMA \\
4.6 & Communication problems & All agencies \\
& & involved in flood \\
& & operation \\
\hline
\end{tabular}

Note: $\mathrm{DID}=$ Department of Irrigation and Drainage; NADMA = National Disaster Management Agency 


\subsection{Limited authorities and lack of enforcement power}

The term 'authority' is used to indicate which public authorities have been given the responsibility for the implementation of Floods Directive and which institutions have the power to undertake, to fund, to regulate or otherwise influence flood risk management interventions (Hegger et al., 2013; Burger and Christen, 2011).

In this case, the Department of Irrigation and Drainage Malaysia (DID) is the main agency responsible for flood management. This role is well regulated in the Ministerial Functions Act 1969 (amendment 2008) P.U. (A) 170. In the act, the role of DID is limited to water resources but includes planning and development of flood, management of hydrology data, management of national water resources, planning and management of river basins, planning and development of infrastructure water management for agriculture, planning and management of flood mitigation, development and management of coastal zone to reduce coastal erosion and problems related to river mouth deposition and National Water Council.

However, DID has limited authority and enforcement power to steer the flood risk management, especially in terms of flood mitigation for every new development. Every development in Malaysia must get Planning Permission (Kebenaran Merancang) before the developer can start any new development. Firstly, this Planning Permission must be submitted to the One Stop Centre (OSC) in Local Authority. Secondly, OSC will alert all technical agencies involved to give a technical review, and DID is one of the technical agencies responsible for giving a technical review on the development proposal. Thirdly, the Planning Department will access technical reviews by technical agencies. Fourthly, technical meeting by local authority followed by meeting from OSC. Lastly, the Planning Permission application will either be granted or rejected. Based on the interview to government officials from DID, this study found that Local Authority usually will overrule any technical review and decision by DID. This is because DID can only give technical advice, but DID has no authority to reject the development. In the flood-prone area or development that could lead to flood, DID will endorse an official letter to reject the development application or approve with conditions. Usually, the condition consists of a specific size of a retention pond, protecting river reserves or specific ground level for development in a flood-prone area. Nevertheless, due to the limitation of power, there is nothing DID can do other than giving advice. This study found that DID headquarters (federal level) supported by DID State and District had requested for law amendment, to allow more power to DID to prohibit or restrict development in the flood-prone area or enforce strict conditions, but the request was never granted and never passed in the parliament.

NADMA works at a federal level for disaster management. This agency has the overall responsibility for the implementation of Directive No. 20, and in this function, cooperates closely with other flood-related agencies. However, as stated by Elias et al., (2013) and Yusoff et al., (2018), Directive No. 20 is just a document that provides guidelines on disaster management, and does not include comprehensive flood risk management. There is no specific law for NADMA to influence flood risk management. NADMA too is not listed as one of the agencies to review development plans, and have no say in any urban or rural development, even though the development will lead to a higher risk of flood. As for now, NADMA requested to the government for more authority so that NADMA can overrule Local Authority decision in every development 
that is prone to flooding. To be more specific, NADMA requests for authority to be involved in the Planning Department and participate in OSC to ensure every development will comply with 'Disaster Risk Reduction'. This agency requested a law amendment to give them more power and requests for amendment of Directive No. 20 to Directive NADMA No. 1.

\subsection{Collaborative risk sharing and risk management at all levels of government}

The roles and responsibilities of some government entities and private property, historic preservation, and environmental interests are in conflict and in competition with each other, which can impede effective flood risk management (Traver, 2014). Our findings show that there was no system to resolve conflicting priorities between the numerous flood-related agencies that each had control of different parts of the FRM. The agencies involved in this study stated that conflict usually occurs when dealing with the responsibility of flood mitigation. In most of the cases, conflict occurs among the DID, Local Authority and Land and District Office. Our respondents agreed that reducing the risk of one stakeholder might shift it to another stakeholder, which usually leads to shirk of their responsibility.

Other weaknesses in collaborative FRM in between agencies were found in approval of development in a flood-prone area. Incorporating resilience in new development requires the involvement of local authority that has jurisdiction over land use development and building codes. However, this was often excluded from consideration due to barriers involved between federal, state and local authority (refer to sub-topic 4.1 and 4.3 ).

Although the existence of NADMA as the coordinator might seem to show a smooth flood risk management from the outside, the reality is the opposite (as explained in the previous sub-topic, NADMA has no authority). This issue can be solved by a declaration of shared risk across all levels of government. Traver (2014), emphasized the importance to establish a strategy of collaborative management of the risks of flooding that focuses on optimal use of limited resources to achieve common goals. Unfortunately, since Malaysia has no specific law and policy that deal directly with flood and collaborative FRM, sustainable strategies that requires coordination between agencies are nearly impossible.

\subsection{Cooperation among agencies}

For a country with frequent flooding like Malaysia, there has been some progress and collaboration at the government level concerning flood risk management. However, one of the obstacles is to get cooperation to implement flood risk reduction measures at the state and district levels.

NAHRIM's function is to provide expert consultancy services on water and environment to the public and private sector, and research on water, climate change and environment. NAHRIM has conducted research on climate change, downscaling application for flood risk management and other flood related research. However, none of the other flood-related government agencies have used the findings from NAHRIM for flood risk management in Malaysia. The same case can be made for PLANMalaysia (formerly known as Town and Country Planning Malaysia); they have conducted detailed study reports on disaster mitigation such as 'action plan for land use of Pahang River' (Laporan Pelan Tindakan Pembangunan Bersepadu Guna Tanah di Lembangan 
Sungai Pahang), land adjustment based on risk study, and other studies, but when the nonstructural mitigation plans were submitted to the Local Authority, PLANMalaysia did not receive cooperation from the Local Authority (LA) to implement nor consider the content for future development. PLANMalaysia is hoping for partnership and cooperation so that new development approved by LA will be more sustainable and towards disaster risk reduction. As stated in 4.1, other than authority issue, DID did not receive cooperation from LA (specifically the planning department) and Land and District Council for flood mitigation. Furthermore, during flood response, the Civil Defence Force (APM) have to work together with the Fire and Rescue Department during rescue session. Nevertheless, they are having issues to get cooperation from Fire and Rescue Department, and this problem occurs due to 'ranking' in the uniform units, as Fire and Rescue Department usually holds higher rank in the uniform bodies.

However, our study also finds that cooperation among agencies was good in terms of information sharing. Agencies are responsible for ensuring that evacuation plans are in place, and to do this, they rely on coordination of information from other agencies (weather reporting, safe road, tracking of flood level). When the subject was asked on this matter, we received a positive response in terms of information sharing.

\subsection{Insufficient funding}

Establishment of long term, reliable funding mechanisms for flood risk reduction measures at the federal, state, and local levels are one of the important factors in implementing good FRM (Traver, 2014). However, in a flood prone country like Malaysia, all flood-related agencies stated that insufficient funding is one of the challenges in flood risk management, especially to DID which would require significant funding for the implementation of structural measures for flood mitigation. They also stated that it is hard to get funding from the federal government and the scale of previous year disaster and public interest does influence the amount of funding received.

Other than that, the timeline provided by the federal government to state and district government to use the funding is limited from March to November every year. Since disasterrelated projects take time to plan and developed, the timeline of nine months given is not enough. Another issue is, there is no fund given for maintenance. Therefore, the relevant agencies have a hard time to maintain assets used for flood response and maintain the existing built flood structural measures. There is also limited funding provided for non-structural measures. This could be the results of the new government aim of lower spending and lower budget (Reuters, 2019).

\subsection{Lack of manpower, assets for logistics}

The issues are considerably more complicated at the district level, where the resources are more limited. All interviewed flood-related agencies have stated the issue of not having enough manpower and logistic assets, especially during disaster response in the district area.

For State and District level, all flood-related agencies are mandated to be on duty during flood response; however, usually, the staff involved are flood victims too, mostly in the district area which then results in a lack of manpower. Moreover, the Civil Defence Force and the Fire and 
Rescue Department also do not have enough manpower to perform their response and rescue duty well.

Flood-related agencies acknowledge that they are having issues for humanitarian logistic operations due to short of transportation assets. The agencies highlighted this issue as one of the main challenges to perform their duty in flood risk management, especially during the preparedness and response phase.

This problem remains unsolved because the relevant agencies did not get approval for additional logistics assets from the federal government, even though preparing these logistics activities is crucial to successful disaster response. This finding too clearly shows that emergency preparedness plans in Malaysia lack insight in humanitarian logistics.

\subsection{Communication}

Effective communication is recognized as an essential component of flood risk management. However, a lack of a clear communication strategy has been identified as a major failing in response to dealing with floods (Bradford and O'Sullivan, 2011). Once a year all related agencies will have a meeting in preparation for flooding during monsoon season. Majority of the respondents agreed that meeting once a year is not enough to make a good coordination for flood response. Flood-related agencies should communicate early and frequently to ensure an orderly response plan.

Other than this, the involved government officials in federal, state and district are using 'WhatsApp' as a form of government-to-government communication. However, 'WhatsApp' requires an internet connection to send and receive messages, and based on our interviews, officers on duty for the flood response in Pahang were having a hard time to communicate with each other due to the internet slow-down during rain. In this case, 'WhatsApp' is not the best medium for government-to-government communication.

The second communication medium is Government Integrated Radio Network (GIRN). All government agency involved with 'response' phase will use GIRN to communicate with each other. However, this study found that GIRN usually jammed during flood response when many officers are using it. The lack of frequent communication and instability of communication medium among flood-related agencies in Malaysia shows a clear gap in a flood communication plan which can lead to failure in flood response. It is crucial to improve agencies communication capacity so that we can minimize chaos and create good coordination once flood occurs.

\subsection{Discussion}

Flood risk management in Malaysia is a top-down government responsibility, and Malaysians are heavily reliant to the flood-related government agencies to manage the flood. However, very few studies have previously examined the real issues and challenges of flood-related agencies in Malaysia. This study started with the assumption that there are hidden challenges faced by these agencies to better-managed flood. Figure 1 depicts the direct and secondary impact of these challenges discussed in the sections above, to flood-related agencies. 


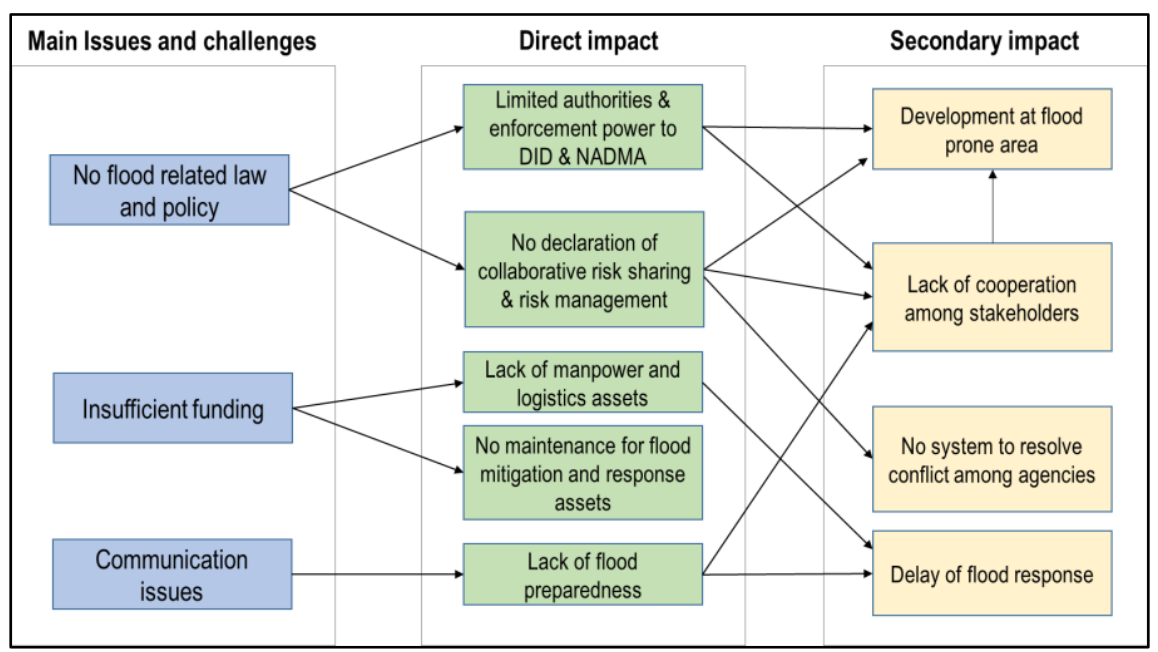

Figure 1: Issues and challenges of flood related agencies

To our knowledge, the main problems are lack of flood management-related legislation to control flood occurrences which lead to lack of authority and enforcement capability. The Land Conservation Act 1960 (aimed at protecting soil erosion and silting hence preventing downstream flooding), Town and Country Planning Act 1976, Environmental Quality Act 1974, Environmental Quality Order 1987, National Land Code 1965, Irrigation Areas Act 1953 amendment 1989, Water Acts 1920, the Drainage Works Ordinance 1954, Street, Drainage and Building Act 1974, Irrigation Areas Ordinance, and the Housing Development Act (Licensing and Control) 1965, none of it deals directly with flood protection or flood control. There is, a need to pass a new Flood Act, Flood Enactment or River Law dealing directly with flood protection and flood control (Keizrul Abdullah, 2002 in Chan 2012). The government need to adjust executive action, legislation and flood control policy in order to manage the flood risks well.

One of the direct impact of no specific flood law and policy, is lack of authority and enforcement power to relevant agencies to steer the FRM. The government, the members of Cabinet, need to take proactive measures and give relevant authority and enforcement power to DID or NADMA to overrule any development proposal that is not sustainable and could create greater risk for disaster. Although the existence of NADMA as the coordinator might seem to show a smooth flood risk management from the outside, the reality is the opposite (as explained in the previous subtopic, NADMA has no authority) hence has no power to steer a well-coordinated and cooperative FRM among agencies.

Another issue is that there is no declaration of collaborative risk sharing and risk management at all levels of government. Collaborative risk sharing and risk management is important in FRM and many countries have been adapting this collaborative risk sharing as a part of good flood risk governance. Malaysia should adapt collaboration risk sharing to link different organizations, agencies and directly establish collaborative FRM mechanisms in order to reduce the current 
shirking from responsibility issue (refer to sub-topic 4.2). Collaborative risk sharing and risk management at all levels of government and by all stakeholders is required to promote effective FRM and to make sure that risk is reduced and not simply transferred to another region (Traver, 2014). This declaration too will help to form cooperation among agencies directly.

Furthermore, lack of cooperation among agencies in permitting development in flood-prone areas "is also problematic". Incorporating resilience in new development requires the involvement of local authority that has jurisdiction over land use development and building codes. However, this was often excluded from consideration due to barriers involved between federal, state and local authority (refer to sub-topic 4.1 and 4.3). Malaysia is far behind in 'Disaster Risk Reduction', and it is important to get Federal, State, District Government focused towards the same aim, which is to reduce the disaster. Based on the status quo, the success of flood risk management rests upon State Government and Local Authority and upon individual property owners in flood-prone areas. Unfortunately, since Malaysia has no specific related law and policy that deal directly with floods and collaborative FRM, sustainable strategies that require coordination between vary stakeholders are nearly impossible. In this case, it is important to issue an executive order directing the State, District Government and Local Authority to consider flood hazards in all developments. By doing so, cooperation among flood-related agencies will start to form directly and indirectly.

Funding is one of the neglected issues by the government. Government expenditures and actions to reduce flood damage can be seen from the insufficient funding issues faced by floodrelated agencies. Since Malaysia is experiencing massive flood annually, the expenditures should be more extensive, and it is important to have dedicated funding for holistic flood risk management. The decision makers in Malaysia need to understand the flood risks and take this issue into account when developing policies and actions. Without sufficient funding, relevant agencies will not be able to perform the mitigation, preparedness, response and recovery phases in flood risk management well. The lack of investment funding for floods is key to what appears to be limited success in flood risk management Malaysia. In addition, agencies involved in rescuing flood victims face many challenges in transporting victims to a safe place due to lack of logistics assets. This clearly shows how the federal government may have overlooked the issue of preparing well-maintained assets and how logistics are essential in flood preparedness and response. In other words, planning of flood emergency logistics has received little attention from the relevant stakeholder. It has been acknowledged that the government needs to play a key role in preparing logistic for effective disaster response (Moe \& Pathranarakul, 2006; Leeuw et al., 2009).

Good communication is a vital part of disaster response. The current 'once a year meeting' for flood preparation is not enough and show lack of responsibility for flood risk communication. Furthermore, there is a necessity to find alternative communication medium among agencies. By looking at the current issues faced by the agencies, the use of GIRN and WhatsApp are not safe. Moreover, in 2013, major floods and non-stop rain in Pahang, led to a major blackout with no electricity, because generally the responsible body for electricity in Malaysia shuts down the electric supply when water reaches a dangerous level (Ong, 2013). Since WhatsApp highly depends on internet and mobile phone that needs to be charged with electric, alternative medium 
of communication is needed. Relevant agencies also faced many problems with the use of GIRN which usually jams during a major flood. Since Malaysia is experiencing major floods annually, the government should provide effective communication medium for flood preparedness and response.

This study has several strengths. First, we were able to identify the current challenges and issues faced by the agencies. Second, we were able to prove how lack of legislation, authority and weakness in the collaborative risk sharing and FRM at all levels of government resulted in under-performing flood-related agencies. Third, our findings on insufficient funding, lack of logistic assets and lack of cooperation from Local Authority show lack of efforts from the government to boost resilience. Fourth, these findings can be used in assessing areas needed for comprehensive and effective flood risk management. The in-depth interview has enabled us to explore more on the challenges. However, the important limitation of this study is that the number of interviewees was relatively small, which may also limit the transferability of the results to a more complex context.

Our results are consistent with the study by Chamindi et al. (2016) in Sri Lanka. The study by Chong and Kamarudin (2017) is the only published article indicating the issues and challenges from the perspective of disaster-related agencies in Malaysia. However, their study was not specific to flood-related agencies. Therefore, our study adds to the knowledge in understanding weaknesses that will threaten the risk flood management process.

\subsection{Conclusion}

This paper has identified the issues and challenges of flood agencies in Malaysia. The challenges that we have identified therefore assists in our understanding of the hindrance faced by the agencies.

However, further work needs to be done to urge the government, specifically the ministers as the nation decision-maker to consider and solve the issues and challenges faced by the floodrelated agencies in order to strengthen the agencies capacities for better and comprehensive flood risk management. As a country with frequent flooding, the government need to develop a unified national vision and supporting organizational framework for flood risk management. $A$ comprehensive organizational framework will help in better coordination between agencies.

A new authority distribution supported by law should be regulated to avoid overlapping and overrule of decisions that do not favour flood resilient development. The role of NADMA should be well regulated as the sole coordinator to solve the lack of cooperation among agencies. Specific flood policies and flood act should be formulated and taken into serious considerations by the government to overcome current shortcomings.

It is imperative to solve the issues and challenges faced in order to strengthen the agencies capacities for more excellent and comprehensive flood risk management in Malaysia. New research should examine how we can solve the issues of these agencies and examine how to reach a good flood risk governance in Malaysia. A successful, legitimate flood governance would 
establish a comprehensive distribution of authority, responsibility and resources for flood risk management which could directly create better and reliable flood-related agencies.

\section{Acknowledgement}

Utmost appreciation to all officers from flood-related agencies who take part in the interview.

\section{References}

Austin, O.C., \& Baharuddin, A.H. (2012). Risk in Malaysian agriculture: The need for a strategic approach and a policy refocus. Kajian Malaysia, 30(1), 21-50.

Burger, P \& Christen, M. (2011), Towards a capability approach of sustainability, Journal of Cleaner Production, vol. 19, pp. 787-795

Beamon, B. M. (2004). Humanitarian relief chains: issues and challenges. International Conference on Computers and Industrial Engineering 34: 14-16.

Bradford, R. A., \& O'Sullivan, J. J. (2011). Improving communication strategies for effective flood risk management. In National Hydrology Conference (pp. 52-63).

CFE-DM. (2016). Malaysia Disaster Management Reference Handbook. Retrieved from https://www.cfedmha.org/LinkClick.aspx?fileticket=4RdMetNOcOE\%3D\&portalid=0

Chan, N. W. (1995). Flood disaster management in Malaysia: an evaluation of the effectiveness of government resettlement schemes. Disaster Prevention and Management: An International Journal, 4(4), 22-29. http://doi.org/10.1108/09653569510093405

Chan, N. W. (2012a). Impacts of Disasters and Disasters Risk Management in Malaysia: The Case of Floods', in Sawada, Y. and S. Oum (eds.), Economic and Welfare Impacts of Disaster in East Asia and Policy Responses. In D. P. Aldrich, S. Oum, \& Y. Sawada (Eds.), Economic and Welfare Impacts of Disasters in East Asia and Policy Responses. (pp. 503 551). Tokyo: ERIA Research Project Report 2011-8, Jakarta. http://doi.org/10.1007/978-4-431-55022-8

Chan, N. W. (2012b). Managing Urban Flood Hazards in Malaysia : Emerging Issues and Challenges. Proceedings IACSC 2012 The 3rd International Academic Consortium for Sustainable Cities Symposium, (September 2012), 148-153.

Chong, N. O., \& Kamarudin, K. H. (2017). Disaster risk management in Malaysia: Issues and challenges from the perspective of agencies. Planning Malaysia, 16(1), 105-117. https://doi.org/10.21837/pmjournal.v16.i5.415

Elias, Z., Hamin, Z., \& Othman, M.B. (2013). Sustainable management of flood risks in Malaysia: Some lessons from the legislation in England and Wales. Procedia-Social and Behavioral Sciences, 105(1), 491-497.

Fereday, J. \& Muir-Cochrane, E. (2006). Demonstrating Rigor Using Thematic Analysis: A Hybrid Approach of Inductive and Deductive Coding and Theme Development. International Journal of Qualitative Methods, 5(1), pp.80-92.

Hegger, D., \& Green, C. (2013). Flood risk management in Europe: Similarities and differences between the STARFLOOD consortium countries. Star-Flood. (January). Retrieved from http://www.starflood.eu/documents/2013/06/floodrisk-management-in-europe-similarities-and-differences-between-the-star-flood-consortium-countries.pdf 
Huntjens, P.; Pahl-Wostl, C.; Grin, J. (2010) Climate change adaptation in European river basins. Reg. Environ. Chang. 10, 263-284.

Joffe, H. \& Yardley, L. (2004). Content and thematic analysis, Research methods for clinical and health psychology. California: Sage.

Leeuw, S. De, Vis, I. F. A., \& Jonkman, S. N. (2009). Logistics aspects of emergency preparedness in flood disaster prevention. Serie Research Memoranda, 44, 1-24.

Keizrul Abdullah. (2002). Integrated river basin management. In N. W. Chan (Ed.), Rivers: Towards sustainable development (pp. 3-14). Penang: Universiti Sains Malaysia.

Majlis Keselamatan Negara. (n.d.). Arahan No. 20. Malaysia: Majlis Keselamatan Negara Jabatan Perdana Menteri.

Malalgoda, C., Amaratunga, D., \& Haigh, R. (2016). Overcoming challenges faced by local governments in creating a resilient built environment in cities. Disaster Prevention and Management, 25(5), 628-648. https://doi.org/10.1108/DPM$\underline{11-2015-0260}$

Moe, T. L. and P. Patrhanarakul (2006). An integrated approach to natural disaster management; Public project management and its critical success factors. Disaster Prevention and Management 13(3): 396-413.

Mohamad Yusoff, I., Ramli, A., Mhd Alkasirah, N. A., \& Mohd Nasir, N. (2018). Exploring the managing of flood disaster: A Malaysian perspective. Malaysian Journal of Society and Space, 14(3), 24-36. https://doi.org/10.17576/geo-2018-1403$\underline{03}$

Mohamed M. \& Ragab, M. (2016) Qualitative Analysis Methods Review, 3S Group, College of Business, Technological University Dublin.

Ong, H. S. (2013, December 4). Floods: No let-up in Pahang, blackout in Kuantan as waters rise. The Star. Retrieved from https://www.thestar.com.my/news/nation/2013/12/04/floods-pahang-kuantan-blackout

Othman, M., Ahmad, M.N., Suliman, A., Arshad, N.H., \& Maidin, S.S. (2014). COBIT principles to govern flood management. International Journal of Disaster Risk Reduction, 9, 212-223.

Raungratanaamporn, I., Pakdeeburee, P., Kamiko, A., \& Denpaiboon, C. (2014). Government-communities collaboration in disaster management activity: Investigation in the current flood disaster management policy in Thailand. Procedia Environmental Sciences, 20, 658-667. https://doi.org/10.1016/j.proenv.2014.03.079

Reuters. (2019, October 11). Malaysia 2020 budget: Lower spending, wider fiscal deficit. Reuters. Retrieved from https://www.reuters.com/article/us-malaysia-budget-highlights/malaysia-2020-budget-lower-spending-wider-fiscaldeficit-idUSKBN1WQ0W5

Riessman, C.K. (2005) Narrative Analysis. In: Narrative, Memory \& Everyday Life. University of Huddersfield, Huddersfi eld, pp. 17.

Salmon, et. al. (2011). Coordination during multi-agency emergency response: issues and solutions. Disaster Prevention and Management, 20(2), 140-158.

Shahid, K. W., Xinhai, L., \& Muhammad, R. (2014). Issues and Challenges in Inter-Organizations Disaster Management in Underdeveloped Coastal Areas of Pakistan. International Journal of Academic Research in Business and Social Sciences, 4(5), 140-155. https://doi.org/10.6007/ijarbss/v4-i5/844

Sipon, S., Sakdan, M.F., Mustaffa, C.S., Marzuki, N.A., Khalid, M.S., Ariffin, M.T., Nazli, N.N.N.N., \& Abdullah, S. (2015). Spirituality among flood victims: A comparison between two states. Procedia-Social and Behavioral Sciences, 185(1), 357-360 
Mabahwi, N.A., et.al., Asian Journal of Behavioural Studies (AjBeS), 5(19) May/Aug 2020 (pp.11-24)

Tan, M.L., Ibrahim, A.L., Duan, Z., Cracknell, A.P., \& Chaplot, V. (2015). Evaluation of six high-resolution satellite and ground-based precipitation products over Malaysia. Remote Sensing, 7, 1504-1528.

Traver, R. (2014). Flood risk management call for for a national strategy. (R. Traver, Ed.), Flood Risk Management. Virginia: A 